\title{
PENGARUH LAMANYA INDUKSI PERSALINAN OKSITOSIN \\ TERHADAP KEJADIAN ASFIKSIA NEONATORUM \\ DI RSUD DR. SLAMET KABUPATEN GARUT TAHUN 2018
}

\author{
Dhea Devitasari ${ }^{1}$, Nunung Mulyani, APP, M.Kes ${ }^{2}$, \\ Sariestya R, SST, M.Keb ${ }^{2}$
}

\section{A. ABSTRAK}

Induksi persalinan adalah suatu tindakan terhadap ibu hamil dengan cara pemberian uterotonika untuk merangsang timbulnya kontraksi rahim agar terjadi persalinan. Hal tersebut merupakan penyebab bayi lahir dengan asfiksia neonatorum akibat dari janin tidak mendapatkan oksigen yang cukup di dalam rahim. Mengetahui pengaruh lamanya induksi persalinan dengan oksitosin drip terhadap kejadian asfiksia neonatorum di RSUD Dr. Slamet Kabupaten Garut Tahun 2018.

Metode yang digunakan dalam penelitian ini adalah metode Analitik dengan pendekatan Cross Sectional. Populasi dalam penelitian ini adalah semua ibu bersalin dengan KPD dan diberikan indusi oksitosin drip RSUD Dr. Slamet Garut sebanyak 48 orang dengan teknik pengambilan sampel Accidental Sampling.

Hasil penelitian menunjukkan bahwa dari 48 ibu bersalin dengan KPD di berikan induksi persalinan oksitosin terdapat 2 bayi lahir tidak asfiksia, 4 asfiksia ringan, 35 asfiksia sedang dan 7 asfiksia berat. Ada pengaruh lamanya pemberian induksi persalinan oksitosin terhadap kejadian asfiksia neonatorum dengan nilai sig $=0,000$ lebih kecil daro 0,05.

Kesimpulan dari penelitian ini ada pengaruh lamanya pemberian induksi persalinan oksitosin terhadap kejadian asfiksia neonatorum di RSUD Dr. Slamet Kabupaten Garut Tahun 2018.

\section{Kata kunci: Induksi Persalinan, Asfiksia Neonatorum}




\section{B. LATAR BELAKANG}

Angka kematian ibu dan bayi merupakan tolak ukur dalam menilai derajat kesehatan suatu bangsa, oleh karena itu pemerintah sangat menekankan untuk menurunkan angka kematian ibu dan bayi melalui program-program kesehatan. Dalam pelaksanaan program kesehatan sangat dibutuhkan sumber daya manusia yang kompeten, sehingga tujuan dapat tercapai (Fadzria dan Meliani, 2014).

Berdasarkan penelitian World Health Organization (WHO), diseluruh dunia terdapat kematian bayi khususnya neonatus sebesar 10.000.000 per tahun. Laporan WHO juga menyebutkan bahwa angka kematian bayi (AKB) kawasan Asia Tenggara merupakan kedua yang paling tinggi yaitu sebesar 142 per 1.000 setelah kawasan Afrika. (Katiandagho \& Kusmiayi, 2015). Penyebab kematian bayi baru lahir tertinggi di dunia yaitu asfiksia, kurang lebih $23 \%$ dari sekitar 4 juta kematian neonatus di seluruh dunia setiap tahunnya( Dewi, 2014).

Pada 2016, hasil riset Badan Pusat Statistik (BPS) mencatat bahwa AKB di Indonesia mencapai 25,5. Artinya, ada sekitar 25,5 kematian setiap 1000 bayi yang lahir. Menurut hasil Riset Kesehatan Dasar tahun 2013, tiga penyebab utama kematian perinatal di Indonesia adalah gangguan pernapasan/ respiratory disorders $(35,9 \%)$, prematuritas $(32,4 \%)$ dan sepsis neonatorum (12.0\%) (Kemenkes RI, 2014).

Di Jawa Barat jumlah kematian bayi per Agustus 2017 mencapai 1.634 dengan faktor penyebab tertinggi kedua karena asfiksia neonatorum sebanyak 440, angka kematian tertinggi berada di Kabupaten Garut. Sampai bulan September angka kematian bayi di Kabupaten Garut mencapai 210 kematian, 42 diantaranya meninggal karena asfiksia neonatorum. Menurut data rekam medik di RSUD Dr. Slamet bayi dan 8 diantaranya meninggal dunia (Dinas Kesehatan Kabupaten Garut, 2017 \& Rekam medis RSUD Dr. Slamet Garut, 2017) Asfiksia merupakan kegawatdaruratan bayi baru lahir berupa depresi pernafasan yang berlanjut sehingga menimbulkan berbagai komplikasi. Disamping itu, asfiksia merupakan penyebab mortalitas dan morbiditas, dan paling sering terjadi pada periode segera setelah lahir dan menimbulkan sebuah kebutuhan resusitasi dan intervensi segera untuk meminimalkan mortalitas dan morbiditas.(Maryunani A, dkk, 2010).

Beberapa keadaan pada ibu dapat menyebabkan aliran darah ibu melalui plasenta berkurang, sehingga aliran oksigen ke janin berkurang, hal ini dapat menyebabkan asfiksia pada bayi baru lahir (Wiknjosastro, 2008). Faktor yang dapat menimbulkan asfiksia yaitu faktor tali pusat, faktor bayi dan faktor ibu, salah satunya pengaruh obat diantarnya oksitosin (Manuaba, 2010).

Induksi persalinan adalah suatu tindakan terhadap ibu hamil dengan cara pemberian uterotonika untuk merangsang timbulnya kontraksi rahim agar terjadi persalinan. Indikasi dilakukan persalinan induksi yang yang salah satunya berasal dari janin yaitu postmaturitas, ketuban pecah dini, dan inkompatibilitas rhesus, faktor ibu yaitu IUFD dan dari faktor ibu serta janin yaitu preeklamsia berat (Mansjoer, 2007). Hal tersebut merupakan penyebab bayi lahir dengan asfiksia neonatorum akibat dari janin tidak mendapatkan oksigen yang cukup di dalam rahim (Wiknjosastro, 2008).

Berdasarkan studi pendahuluan yang telah dilakukan oleh peneliti di RSUD Dr. Slamet Garut melalui 
observasi, dari 10 ibu yang bersalin 9 orang diberikan oksitosin drip, 6 bayi yang dilahirkan mengalami asfiksia dan 3 bayi diantaranya tidak asfiksia.

Berdasarkan uraian dalam latar belakang di atas peneliti merasa tertarik untuk mengadakan penelitian dengan judul "Pengaruh lamanya induksi persalinan dengan oksitosin drip terhadap kejadian asfiksia neonatorum di RSUD Dr. Slamet Garut Tahun 2018"

\section{METODOLOGI PENELITIAN}

\section{Rancangan Penelitian}

Metode yang digunakan dalam penelitian ini adalah metode Survey Analitik dengan pendekatan Cross Sectional.

\section{Waktu dan Tempat Penelitian}

Waktu penelitian ini dilaksanakan pada bulan JanuariFebruari 2018, sedangkan tempat penelitian dilakukan di RSUD Dr. Slamet Kabupaten Garut.

\section{Subjek Penelitian}

Populasi dalam penelitian ini adalah semua ibu bersalin dengan ketuban pecah dini (KPD) dan diberikan induksi oksitosin drip di RSUD Dr. Slamet Garut. Teknik pengambilan sampel dalam penelitian ini adalah menggunakan teknik Accidental Sampling yaitu sebanyak 48 orang.

\section{Variabel Penelitian}

$\begin{array}{lrr}\text { Variabel independen } & \text { dari } \\ \text { enelitian ini adalah } & \text { induksi } \\ \text { ksitosin drip, sedangkan variabel } & \text { adalah } & \text { asfiksia } \\ \text { ependen } & \text { adaloh } & \\ \text { eonatorum. } & & \end{array}$

\section{Instrumen Penelitian}

\section{HASIL PENELITIAN}

\section{Hasil Penelitian}

a. Induksi Persalinan dengan Oksitosin
Instrumen dalam penelitian ini adalah instrumen observasi menggunakan lembar observasi berdasarkan keadaan respondenyang dibuat oleh peneliti.

\section{Analisa Data}

a. Analisis Univariat

Analisis univariat yang digunakan untuk memberikan gambaran distribusi frekuensi dari variabel. Rumus perhitungan persentasenya adalah sebagai berikut :

$$
\mathrm{P}=\frac{\mathrm{n}}{\mathrm{N}} \times 100 \%
$$

Keterangan:

P : Persentasi

$\mathrm{N}$ : Banyaknya subjek dalam kelompok

$\mathrm{n}$ : Banyak subjek keseluruhan

b. Analisis Bivariat

Analisis bivariat dilakukan untuk mengetahui adanya hubungan induksi persalinan dengan asfiksia neonatorum, maka menggunakan analisa data dengan menggunakan rumus uji $\mathrm{T}$ tidak berpasangan. 
Tabel 1. Hasil Statistik Lamaya Induksi Persalinan dengan Oksitosin pada Ibu Bersalin di RSUD dr. SlametKabupaten Garut.

\begin{tabular}{ccccc}
\hline Keterangan & $\mathbf{N}$ & Rata-rata & Minimal & Maksimal \\
\hline $\begin{array}{c}\text { Induksi Persalinan } \\
\text { dengan Oksitosin }\end{array}$ & 48 & 10 jam & 2 jam & 26 jam \\
& & 6 menit & 05 menit & 45 menit
\end{tabular}

Tabel 1 menunjukkan bahwa ratarata lamanya induksi persalinan dengan oksitosin pada ibu bersalin di RSUD dr. Slamet Kabupaten Garut

b. Asfiksia Neonatorum adalah 10 jam 6 menit, dengan lama minimal 2 jam 05 menit dan lama maksimal 26 jam 45 menit.

Tabel 2. Hasil Statistik Asfiksia Neonatorum pada Bayi di RSUD dr. Slamet Kabupaten Garut.

\begin{tabular}{cccc}
\hline No & Klasifikasi Asfiksia & $\mathbf{N}$ & $\mathbf{\%}$ \\
\hline 1. & Tidak Asfiksia & 2 & 4,16 \\
2. & Asfiksia Ringan & 4 & 8,33 \\
3. & Asfiksia Sedang & 34 & 72,92 \\
4. & Asfiksia Berat & 8 & 14,58 \\
\hline & JUMLAH & 48 & 100 \\
\hline
\end{tabular}

Tabel 2 menunjukkan bahwa kejadian asfiksia neonatorum pada bayi di RSUD Dr. Slamet Kabupaten Garut jika diurutkan dari yang terbanyak adalah asfiksia sedang yaitu 34 bayi (72,92\%), asfiksia berat 8 bayi (14,58\%), asfiksia ringan 4 bayi $(8,33 \%)$, dan tidak asfiksia 2 bayi $(4,16 \%)$. 
c. Pengaruh Pemberian Induksi Persalinan dengan Oksitosin Terhadap Kejadian Asfiksia Neonatorum.

Tabel 3. Pengaruh Pemberian Induksi Persalinan dengan Oksitosin Terhadap Kejadian Asfiksia Neonatorum di RSUD dr. Slamet Kabupaten Garut Tahun 2018

\begin{tabular}{lcccccccccc}
\hline No & & $\begin{array}{c}\text { Tidak } \\
\text { Asfiksia }\end{array}$ & $\begin{array}{c}\text { Asfiksia } \\
\text { Ringan }\end{array}$ & $\begin{array}{c}\text { Asfiksia } \\
\text { Sedang }\end{array}$ & $\begin{array}{c}\text { Asfiksia } \\
\text { Berat }\end{array}$ & Mean & Std & Thit & Df & Sig \\
\hline 1. & $\begin{array}{c}\text { Induksi } \\
\text { Oksitosin }\end{array}$ & 2 & 4 & 34 & 8 & 5,6 & 8,2 & 4,777 & 47 & 0,000 \\
\hline
\end{tabular}

Berdasarkan Tabel 3 menunjukkan bahwa rata-rata kejadian asfiksia neonatorum sebesar 5,6 (asfiksia sedang), Standar deviasi (Std) sebesar 8,2, nilai $t_{\text {hitung }}$ sebesar 4,777, dan nilai signifikan sebesar 0,000. Nilai signifikan yang diperoleh jika dibandingkan dengan nilai $\alpha$ lebih kecil $(0,000<0,05)$, H0 ditolak. Maka secara statistik bahwa ada pengaruh induksi persalinan dengan oksitosin terhadap kejadian asfiksia neonatorum di RSUD dr. Slamet Kabupaten Garut tahun 2018.

\section{E. PEMBAHASAN}

Berdasarkan hasil penelitian menunjukkan bahwa ada pengaruh induksi persalinan dengan oksitosin terhadap kejadian asfiksia neonatorum di RSUD dr. Slamet Kabupaten Garut tahun 2018. Induksi persalinan dapat berhasil dan tidak memberikan penyulit baik pada ibu maupun janin jika syarat-syarat yang diperlukan terpenuhi antara lain : kehamilan aterm, ukuran panggul normal, tidak ada disproporsi antara pelvic dan janin, janin dalam presentasi kepala dan serviks sudah matang. Data-data dasar tentang keadaan ibu dan janin dikumpulkan sebelum memulai induksi persalinan untuk mengetahui status kesehatan ibu dan janinnya. Selama induksi persalinan harus dilakukan pengkajian terhadap tandatanda vital ibu, output urin, dilatasi servik, pendataran, stasion dan denyut jantung janin sehingga induksi persalinan dapat diberikan secara 
kontraksi harus ditujukan agar kontraksi dapat timbul seperti kontraksi fisiologis dan tidak menimbulkan asfiksia pada bayi baru lahir. (Prawirohardjo, 2009:54).

Hipoksia janin dapat menyebabkan asfiksia bayi baru lahir karena gangguan pertukaran gas $\mathrm{O} 2$ dari ibu ke janin, sehingga terdapat gangguan dalam persediaan $\mathrm{O} 2$ dan dalam menghilangkan $\mathrm{CO} 2$. Gangguan dapat bersifat penyakit menahun yaitu pada ibu hamil yang menderita gizi buruk, penyakit menahun seperti anemia, hipertensi, penyakit jantung dan lain-lain.

\section{F. SIMPULAN DAN SARAN}

Lamanya pemberian induksi persalinan dengan oksitosin pada ibu bersalin di RSUD dr. Slamet Kabupaten Garut adalah minimal 2 jam 05 menit dan paling lama 26 jam 45 menit dengan rata-rata 10 jam 63 menit.

Kejadian asfiksia neonatorum pada bayi baru lahir di RSUD dr. Slamet Kabupaten Garut sebagian besar ada pada kategori asfiksia sedang yaitu sebesar $72,92 \%$.

Terdapat pengaruh induksi persalinan dengan oksitosin terhadap kejadian asfiksia neonatorum di RSUD dr. Slamet Kabupaten Garut dengan nilai signifikan sebesar 0,000.

Saran :

1. Bagi Institusi Pendidikan

Dapat dijadikan referensi sebagai bahan bacaan oleh dosen dan makasiswa untuk meningkatkan pengetahuan
Asfiksia yang terjadi secara mendadak diakibatkan oleh hal-hal yang diderita ibu dalam persalinan.

Faktor dalam persalinan bersifat lebih mendadak dan hampir selalu mengakibatkan hipoksia janin dan berakhir dengan asfiksia bayi.

Berdasarkan uraian tersebut, maka peneliti berpendapat bahwa induksi persalinan dengan oksitosin berpengaruh terhadap kejadian asfiksia, semakin lama ibu bersalin diberikan induksi persalinan dengan oksitosin maka kejadian asfiksia neonatorum akan semakin tinggi.

tentang induksi persalinan dan asfiksia neonatorum.

2. Bagi Instansi Pelayanan Kebidanan

Tetap melaksanakan tugas sesuai standar operasional serta pengawasan yang baik dari tenaga kesehatan untuk mencegah terjadinya komplikasi baik pada ibu maupun janinnya. Petugas pelayanan kebidanan dapat mengembangkan ilmunya agar menekan angka kejadian asfiksia neonatorum ketika bayi lahir. 


\section{G. REFERENSI}

Arikunto, Suharsimi. (2010).

Prosedur Penelitian. Rineka Cipta: Jakarta.

Cuningham, F. Gary dkk. (2006). Obstetri Williams Vol. 1. Buku Kedokteran EGC: Jakarta.

Chris tanto, et al. (2014). Kapita Selekta Kedokteran Edisi IV. Media Aeskulapius: Jakarta.

Dahlan, M. Sopiyudin. (2009). Statistik untuk Kedokteran dan Kesehatan. Salemba Medika: Jakarta.

Depkes. (2009). Buku Kesehatan Ibu Dan Anak. Jakarta.

Indah, Sitti Nur dan Ety Apriliana. (2016). Hubungan antara preeklamsia dalam kehamilan dengan kejadian asfiksi pada bayi baru lahir. Medical Journal: Lampung University.

Kemenkes RI. (2014). Profil Kesehatan Indonesia 2013. Kemenkes RI: Jakarta.

Kevin, P.Hanretty. (2014). Ilustrasi Obstetri. Nuha Medika: Jakarta.

Kosim, MS dkk. (2008). Buku Panduan Manajemen Masalah Bayi Baru Lahir untuk Dokter, Bidan dan Perawat di Rumah Sakit. IDAI Depkes RI: Jakarta.

Mansjoer, Arif. (2007). Kapita Selekta Kedokteran Edisi 3 Jilid II. Media Aesculapius: Jakarta.
Mochtar, R (2012). Sinopsis Obstetri Obstetri Fisiologi Obstetri Patologi Jilid 1. EGC: Jakarta.

Manuaba, I.A.C dkk. (2010). Ilmu Kebidanan. Penyakit Kandungan, dan KB. EGC: Jakarta.

Manuaba, I.B.G. (2013). Ilmu Kebidanan Penyakit Kandungan dan Keluarga Berencana Untuk Pendidikan Bidan. EGC: Jakarta.

Maryunani, Anik dan Eka Puspita. (2013). Asuhan Kegawatdaruratan Maternal dan Neonatal. CV. Trans Info Media: Jakarta.

Notoatmodjo, Soekidjo. (2010). Metodologi Penelitian Kesehatan. PT Asdi Mahastya: Jakarta.

Oxorn, Harry dan William R. Forte. (2010). Ilmu Kebidanan: Patologi dan Fisiologi Persalinan. Yayasan Esentia Medika: Yogyakarta.

Prambudi, R (2013). Penyakit pada Neonatus dalam Neonatologi Praktis Cetakan Pertama. Anugrah Utama Raharja: Bandar Lampung.

Prawirohardjo, Sarwono. (2010). Pelayanan Kesehatan Maternal dan Neonatal. PT. Bina Pustaka Sarwono Prawirohardjo: Jakarta.

Purwoastuti, Th. Endang dan Elishabeth S W. (2015). Asuhan Kebidanan Kegawatdaruratan Maternal \& Neonatal. PT Pustaka Baru: Yogyakarta.

Riwidikdo, Handoko. (2007). Statistik Kesehatan, Mitra Cendikia Press: Yogyakarta.

Rukiyah, A.Y, dkk. (2009). Asuhan Kebidanan II 
(Persalinan). CV. Trans Info Media: Jakarta.

Rohani, dkk. (2011). Asuhan Pada Masa Persalinan. Salemba Medika: Jakarta.

Saifuddin, AB. (2002). Pelayanan Kesehatan Maternal dan Neonatal. PT. Bina Pustaka Sarwono Prawirohardjo: Jakarta.

Saifuddin, A.B. (2009). Panduan Praktis Pelayanan Kesehatan Maternal dan Neonatal. EGC: Jakarta.

Saifuddin, A.B. (2010). Buku Acuan Nasional Pelayanan Kesehatan Maternal Dan Neonatal. PT. Bina Pustaka Sarwono Prawirohardjo: Jakarta.

Sondakh, Jenny J.S. (2013). Asuhan Kebidanan Persalinan dan Bayi Baru Lahir. Erlangga: Jakarta.
Suhadi, Agung, dkk. (2013). Buku Saku Pelayanan Kesehatan Ibu di Fasilitas Kesehatan Dasardan Rujukan. Kementerian Kesehatan Republik Indonesia: Jakarta.

Sukarni, Icesmi \& Margareth ZH. (2013). Kehamilan, Persalinan dan Nifas. Nuha Medika: Yogyakarta.

Sulistyawati A, Nugraheny E. (2010). Asuhan kebidanan pada ibu bersalin. Salemba Medika: Jakarta.

Suwarjana, I Ketut. (2012). Metodelogi Penelitian Kesehatan. CV Andi Offest (Penerbit Andi): Yogyakarta.

Winkjosastro, Hanifa. (2008). Ilmu Kandungan. EGC: Jakarta 